\title{
Prevalence and Predictors of Complications of Radiofrequency Catheter Ablation for Atrial Fibrillation
}

\author{
TIMIR S. BAMAN, M.D., KRIT JONGNARANGSIN, M.D., AMAN CHUGH, M.D., \\ ARISARA SUWANAGOOL, M.D., AURELIE GUIOT, M.D., ARIN MADENCI, B.A., \\ SPENCER WALSH, B.A., KARL J. ILG, M.D., SANJAYA K. GUPTA, M.D., \\ RAKESH LATCHAMSETTY, M.D., SUVEER BAGWE, M.D., JAMES D. MYLES, PH.D., \\ THOMAS CRAWFORD, M.D., ERIC GOOD, D.O., FRANK BOGUN, M.D., \\ FRANK PELOSI, JR, M.D., FRED MORADY, M.D., and HAKAN ORAL, M.D.
}

From the Division of Cardiovascular Medicine, University of Michigan, Ann Arbor, Michigan, USA

\begin{abstract}
Complications of Atrial Fibrillation Ablation. Introduction: Up to 6\% of patients experience complications after radiofrequency catheter ablation (RFA) of atrial fibrillation (AF). The purpose of this study is to determine the prevalence and predictors of periprocedural complications after RFA for AF.

Methods and Results: The subjects were 1,295 consecutive patients (age $=60 \pm 10$ years) who underwent RFA $(n=1,642)$ for paroxysmal $(53 \%)$ or persistent AF $(47 \%)$ from January 2007 to January 2010 . A complication occurred in 57 patients $(3.5 \%)$; a vascular access complication in $31(1.9 \%)$; pericardial tamponade in $20(1.2 \%)$; a thromboembolic event in $4(0.2 \%)$; deep venous thrombosis in $1(<0.01 \%)$; and pulmonary vein stenosis in 1 patient $(<0.01 \%)$. There were no procedure-related deaths. On multivariate analysis, female gender $(\mathrm{OR}=2.27 ; \pm 95 \% \mathrm{CI}: 1.31-2.57, \mathrm{P}<0.01)$ and procedures performed in July or August $(\mathrm{OR}=\mathbf{2 . 1 0} ; \pm 95 \% \mathrm{CI}: \mathbf{1 . 1 6}-\mathbf{3 . 8 0}, \mathrm{P}=\mathbf{0 . 0 1})$ were independent predictors of any complication. For vascular complications, treatment with clopidogrel $(O R=4.40 ; \pm 95 \% \mathrm{CI}: 1.43-13.53, P=0.01)$, female gender $(\mathrm{OR}=3.65 ; \pm 95 \%$ CI: $1.72-7.75, \mathrm{P}<0.01)$ and performing RFA in July or August $(\mathrm{OR}=\mathbf{2 . 7 1}$; $\pm 95 \%$ CI: $1.25-5.87, P=0.01$ ) were independent predictors. The only predictor of cardiac tamponade was prior RFA (OR = 3.32; $\pm 95 \%$ CI: 0.95-11.61; $P<0.05)$.

Conclusion: Prevalence of perioperative complications for RFA of AF is $3.5 \%$ and vascular access complications constitute the majority. The need for clopidogrel therapy should be carefully considered prior to RFA. At teaching institutions close supervision should be exercised during vascular access early in the year. Improvements in ablation technology and elimination of the need for repeat procedures may decrease the risk of pericardial tamponade. (J Cardiovasc Electrophysiol, Vol. 22, pp. 626-631, June 2011)
\end{abstract}

atrial fibrillation, catheter ablation, complications, pulmonary vein stenosis, stroke

\section{Introduction}

Radiofrequency catheter ablation (RFA) has proven to be an effective treatment modality to eliminate atrial fibrillation (AF). It is likely that worldwide adoption of RFA for AF will continue to increase. Although effective, RFA also carries a small but finite risk of serious complications. Major complications after RFA of AF have been reported in $1.4 \%$ to $6 \%$ of patients in prior studies. ${ }^{1-3}$

The purpose of this study is to determine the risk factors associated with perioperative complications in a large cohort

Funded in parts by the NIH through CTSA grant UL1RR024986 and the Leducq Foundation.

Dr. Oral reports participation on research grants supported by St. Jude Medical and Boston Scientific. He serves as a consultant to and/or on the advisory boards of Medtronic and Ablation Frontiers. Other authors: No disclosures.

Address for correspondence: Hakan Oral, M.D., Cardiovascular Center, SPC 5853, 1500 E. Medical Center Dr., Ann Arbor, MI 48109-5853, USA. Fax: (734) 936 7026; E-mail: oralh@umich.edu.

Manuscript received 30 August 2010; Revised manuscript received 18 October 2010; Accepted for publication 12 November 2010.

doi: $10.1111 / \mathrm{j} .1540-8167.2010 .01995 . x$ of patients with AF who underwent RFA using the same ablation technology at an academic teaching institution.

Methods

\section{Study Subjects}

The subjects of this study were 1,295 consecutive patients who underwent 1,642 RFA procedures to eliminate paroxysmal $(n=870,53 \%)$ or persistent $\mathrm{AF}(\mathrm{n}=772,47 \%)$ between January 2007 and January 2010. Consecutive patients were enrolled from a 3-year interval during which ablation technique and the devices used for ablation were similar among operators. The mean age of the patients was $60 \pm 10$ years (range: 23-84 years). Of the procedures performed, 1,217 (74\%) were in men and $425(26 \%)$ were in women. The mean left atrial size and left ventricular ejection fraction were $41 \pm 12 \mathrm{~mm}$ and $0.54 \pm 0.22$, respectively. The clinical characteristics of the patients (per procedure) are shown in Table 1.

\section{Electrophysiologic Study and RFA}

All patients provided informed written consent. An electrophysiologic study was performed in the fasting state. All antiarrhythmic drugs except amiodarone were discontinued 
TABLE 1

Characteristics of Procedures

\begin{tabular}{|c|c|c|c|c|}
\hline & $\begin{array}{l}\text { Total Procedures } \\
\quad(\mathrm{n}=\mathbf{1 , 6 4 2})\end{array}$ & $\begin{array}{l}\text { No Complications } \\
\quad(\mathbf{n}=\mathbf{1 , 5 8 5})\end{array}$ & $\begin{array}{l}\text { Complications } \\
\quad(\mathrm{n}=\mathbf{5 7})\end{array}$ & $\mathbf{P}$ \\
\hline Female gender & $425(26)$ & $400(25)$ & $25(44)$ & $<0.01$ \\
\hline Age (years) & $60 \pm 10$ & $60 \pm 10$ & $62 \pm 10$ & 0.14 \\
\hline Height (in) & $70 \pm 5$ & $70 \pm 4$ & $69 \pm 4$ & 0.10 \\
\hline Weight (lbs) & $215 \pm 65$ & $214 \pm 48$ & $208 \pm 40$ & 0.32 \\
\hline Persistent AF & $772(47)$ & $751(48)$ & $21(37)$ & 0.14 \\
\hline Previous AF ablation & $634(39)$ & $616(42)$ & $18(35)$ & 0.40 \\
\hline Hypertension & $854(53)$ & $819(52)$ & $35(61)$ & 0.22 \\
\hline Coronary artery disease & $259(16)$ & $248(16)$ & $11(19)$ & 0.49 \\
\hline CABG surgery & $182(11)$ & $175(11)$ & $8(14)$ & 0.52 \\
\hline Hyperlipidemia & $813(50)$ & $784(50)$ & $29(51)$ & 1.00 \\
\hline Diabetes mellitus & $212(13)$ & $206(13)$ & $6(10)$ & 0.69 \\
\hline Hypertrophic cardiomyopathy & $22(1)$ & $20(1)$ & $2(4)$ & 0.12 \\
\hline Gastroesophageal reflux disease & $298(18)$ & $287(18)$ & $11(19)$ & 0.86 \\
\hline Hypothyroidism & $278(17)$ & $271(17)$ & $7(12)$ & 0.37 \\
\hline Tobacco use & $166(10)$ & $159(10)$ & $7(12)$ & 0.65 \\
\hline Clopidogrel & $64(4)$ & $59(4)$ & $5(9)$ & 0.07 \\
\hline Aspirin & $626(39)$ & $601(39)$ & $25(45)$ & 0.41 \\
\hline ACE inhibitors & $371(23)$ & $361(23)$ & $10(18)$ & 0.42 \\
\hline Beta blockers & $1,033(65)$ & $999(65)$ & $34(61)$ & 0.57 \\
\hline Amiodarone therapy & $115(7)$ & $114(7)$ & $1(2)$ & 0.18 \\
\hline Antiarrhythmic drug therapy (other than amiodarone) & $571(36)$ & $551(36)$ & $20(36)$ & 1.00 \\
\hline ARB & $198(12)$ & $191(12)$ & 7 (13) & 1.00 \\
\hline Calcium channel blockers & $528(33)$ & $505(33)$ & $23(41)$ & 0.20 \\
\hline Digoxin & $269(17)$ & $256(17)$ & $13(23)$ & 0.20 \\
\hline Statin & $725(45)$ & $699(45)$ & $26(46)$ & 0.89 \\
\hline Ejection fraction & $0.54 \pm 0.22$ & $0.56 \pm 0.10$ & $0.55 \pm 0.11$ & 0.65 \\
\hline Left atrial size (mm) & $41 \pm 12$ & $44 \pm 7$ & $43 \pm 7$ & 0.20 \\
\hline Procedure in July or August & $286(17)$ & $269(17)$ & $17(30)$ & 0.01 \\
\hline Total RF time & $67 \pm 29$ & $68 \pm 29$ & $62 \pm 24$ & 0.24 \\
\hline Total fluoroscopy time & $63 \pm 24$ & $63 \pm 24$ & $61 \pm 21$ & 0.64 \\
\hline Procedure time & $280 \pm 90$ & $281 \pm 80$ & $279 \pm 87$ & 0.81 \\
\hline CTI line & 249 (19) & 244 (19) & $5(16)$ & 0.82 \\
\hline Mitral/roof line & $795(48)$ & $772(49)$ & $23(40)$ & 0.22 \\
\hline Ablation of complex electrograms & $570(35)$ & $551(35)$ & $19(33)$ & 0.89 \\
\hline
\end{tabular}

Values are $\mathrm{n}(\%)$ or mean $\pm \mathrm{SD}$. $\mathrm{AF}=$ atrial fibrillation; $\mathrm{CABG}=$ coronary artery bypass graft surgery; $\mathrm{ACE}=$ angiotensin converting enzyme inhibitors; $\mathrm{ARB}=$ angiotensin receptor blockers; $\mathrm{CTI}=$ cavotricuspid isthmus; $\mathrm{RF}=$ radiofrequency.

at least 4-5 half lives before the procedure. Amiodarone was discontinued 8 weeks before the procedure. Three 8.0 to $8.5 \mathrm{Fr}$ sheaths were inserted into the same femoral vein in all cases. A multipolar electrode catheter was placed in the coronary sinus for recording electrograms and for atrial pacing. After transseptal access, systemic anticoagulation was achieved with intravenous heparin to maintain an activated clotting time of 300-350 seconds. A decapolar ring catheter (Lasso, Biosense Webster, Diamond Bar, CA, USA) was used to map pulmonary veins (PVs). An electroanatomical mapping system (Carto, Biosense Webster) was used to reconstruct the 3-dimensional geometry of the left atrium and PVs. Bipolar electrograms were displayed and recorded at filter settings of 30 to $500 \mathrm{~Hz}$ (EPMed Systems).

All patients underwent antral PV isolation to isolate the PVs using an open-irrigation, 3.5-mm-tip deflectable catheter (Thermocool, Biosense Webster). Only an open-irrigationtip radiofrequency ablation catheter was used in all patients in this study. Patients who underwent catheter ablation using any other device were excluded. ${ }^{4}$ Ablation of complex fractionated atrial electrograms in the left and right atria, coronary sinus, and linear ablation were performed at the discretion of the operator. Radiofrequency energy was delivered at a maximum power output of $35 \mathrm{~W}$ at a flow rate of $30 \mathrm{~mL} / \mathrm{min}$ and a maximum temperature of $48^{\circ} \mathrm{C}$. The power was reduced to 20 to $25 \mathrm{~W}$ at a flow rate of $17 \mathrm{~mL} / \mathrm{min}$ during applications of energy near the PV ostia, posterior left atrium, or in the coronary sinus. The esophagus was visualized by barium swallow or an esophageal probe, and lesions close to the esophagus were avoided as described previously. ${ }^{5}$ Anticoagulation was not reversed with protamine in any of the patients after the procedure.

\section{Postablation Management and Follow-Up}

All patients were observed and had electrocardiographic monitoring during an overnight hospital stay after the ablation. Patients were discharged home taking warfarin and low molecular weight heparin as a bridge to therapeutic anticoagulation, if necessary. RFA was performed with a therapeutic international normalized ratio (INR) (>2.0) in 198 patients who therefore did not require low molecular weight heparin (LMWH). Patients who were on an antiarrhythmic agent prior to the procedure were maintained on the same regimen for 8-12 weeks after the ablation procedure.

All patients were seen in an outpatient clinic 3 months after the procedure and every 3-6 months thereafter. A repeat ablation procedure was offered to all patients with recurrent atrial arrhythmias. During repeat ablation, antral PV isolation was confirmed and repeated as necessary. At the 


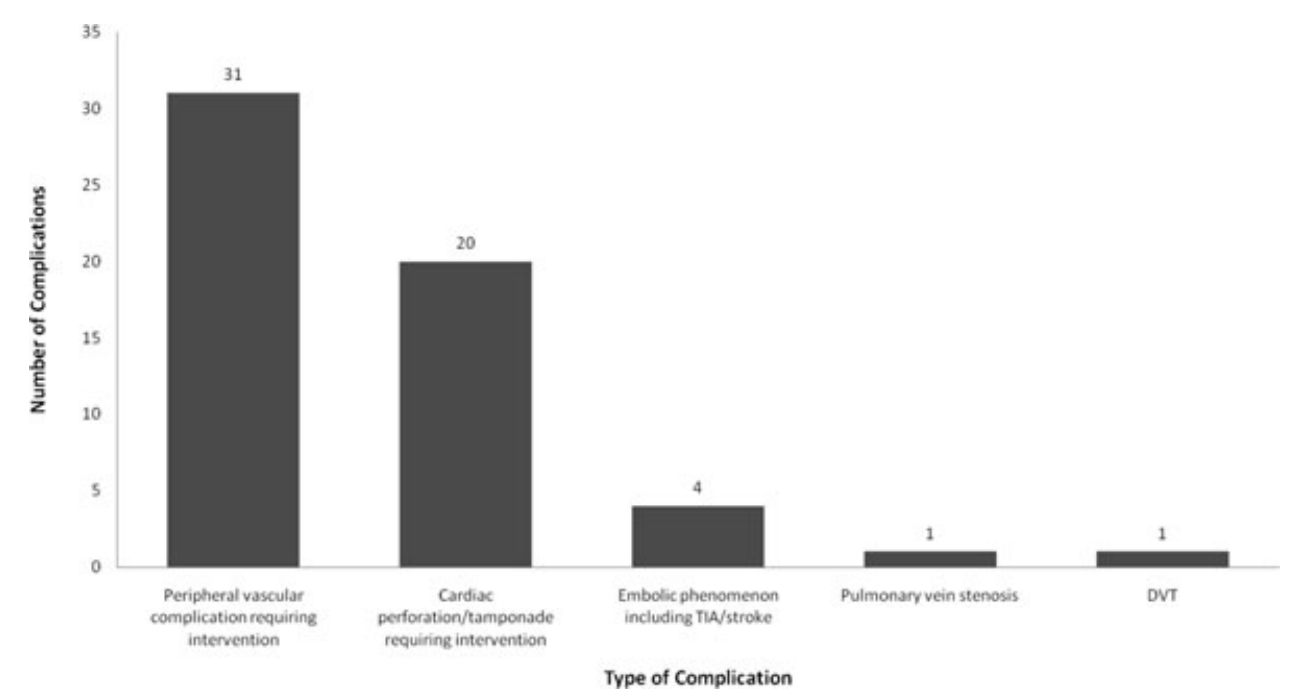

Figure 1. Types and frequency of complications after RFA for AF. DVT= deep venous thrombosis.

discretion of the operator, complex fractionated atrial electrograms (CFAEs) were also targeted and eliminated and/or linear ablation was performed.

Warfarin was discontinued in patients who were confirmed to be in sinus rhythm beyond 3 months after the final ablation procedure as long as there was no history of thromboembolic events or another indication to continue anticoagulant therapy.

\section{Study Protocol}

The study protocol was approved by the Institutional Review Board. In this registry, data were acquired prospectively. The primary endpoint of the study was major complications that occurred $\leq 3$ months after an index or repeat ablation procedure. Major complications were defined as: (1) a pericardial effusion that required percutaneous or surgical drainage or repair; (2) a peripheral vascular complication that required blood transfusion or resulted in arteriovenous fistula, or pseudoaneurysm requiring percutaneous or surgical intervention or longer hospital stay; (3) deep venous thrombosis (DVT); (4) any thromboembolic event including transient ischemic attack (TIA) or stroke; (5) pulmonary vein stenosis; (6) atrioesophageal fistula; (7) phrenic nerve palsy; and (8) death.

\section{Statistical Analysis}

Continuous variables were expressed as mean \pm 1 standard deviation and were compared using a $t$-test. Normality assumptions were first checked and found to be satisfied; therefore, nonparametric tests were not used. Categorical variables were expressed as counts and percentages and compared using a Fisher's exact test. Univariate parameters possibly associated $(\mathrm{P}<0.15)$ with AF complications were then included as candidate predictors in a stepwise multivariable logistic regression analysis. All analyses were performed using SAS 9.2 (SAS Institute Inc., Cary, NC, USA). Results of the logistic regression model were presented as odds ratios with $95 \%$ confidence intervals. In the case of the association between cardiac tamponade and previous RFA, the Fisher's exact test and the Score test in the logistic regression model both showed a significant association at a $\mathrm{P}<0.05$. A P $<$ 0.05 indicated statistical significance.

\section{Results}

\section{Prevalence of Complications}

A complication occurred in 57 of 1,295 patients $(4.4 \%)$ and in 57 of 1,642 procedures $(3.5 \%)$. In descending order of prevalence, the complications were: a peripheral vascular complication requiring transfusion, intervention, or prolonged hospital stay in 31 patients $(2.4 \%$ per patient and $1.9 \%$ per procedure); a pericardial effusion requiring intervention in 20 patients $(1.5 \%$ per patient and $1.2 \%$ per procedure); a thromboembolic event in 4 patients $(0.3 \%$ per patient and $0.2 \%$ per procedure) including a TIA in 2 patients, a stroke with residual symptoms in 1 patient, and mesenteric embolism in 1 patient; PV stenosis of $90 \%$ involving the left superior pulmonary vein in 1 patient $(<0.01 \%)$; and DVT of the lower extremity in 1 patient $(<0.01 \%)$. There was no phrenic nerve palsy, atrioesophageal fistula, or procedure-related mortality (Figure 1). Among the 1,295 patients, none experienced more than one complication.

\section{Procedural Characteristics, Repeat Ablation, and Complications}

The mean duration of RFA was $280 \pm 90$ minutes and the mean duration of radiofrequency energy application was $67 \pm 29$ minutes. Six hundred and thirty-four of 1,642 procedures were a repeat ablation (39\%).

There was no association between the ablation strategy $(\mathrm{P}=0.2)$, duration of radiofrequency energy application $(\mathrm{P}=0.2)$, and total procedure time $(\mathrm{P}=0.8)$ and the probability of developing complications. However, a previous RFA for $\mathrm{AF}$ was associated with a higher likelihood of pericardial tamponade $(\mathrm{OR}=3.32 ; \pm 95 \%$ CI: $0.95-11.61, \mathrm{P}<0.05$ Fisher's exact test).

\section{Case Volume, Month of the Year, and Complications}

There was no association between annual procedure volume and complications $(\mathrm{P}=0.2)$. However, the probability of overall complications was higher in the months of July or August than the other months of the year $(\mathrm{OR}=2.10 ; \pm 95 \%$ 
TABLE 2

Univariate Predictors of Complications

\begin{tabular}{lccr}
\hline & OR & $\mathbf{1 9 5 \%}$ CI & \multicolumn{1}{c}{ P } \\
\hline Age (years) & 1.02 & $0.99-1.05$ & 0.14 \\
Female gender & 2.32 & $1.36-3.95$ & $<0.01$ \\
Persistent atrial fibrillation & 1.54 & $0.89-2.67$ & 0.12 \\
$\begin{array}{l}\text { Procedure performed } \\
\quad \text { in July or August }\end{array}$ & 2.08 & $1.16-3.72$ & 0.01 \\
Clopidogrel & 2.50 & $0.99-6.47$ & 0.06 \\
\hline
\end{tabular}

CI: $1.16-3.80, \mathrm{P}=0.01)$. There was no relationship between the time of the year, case volume, and risk of pericardial tamponade $(\mathrm{P}=0.2)$.

\section{Predictors of Complications}

On univariate analysis, among the clinical variables listed in Table 1, female gender $(\mathrm{OR}=2.32 ; \pm 95 \%$ CI: 1.36 $3.95, \mathrm{P}<0.01$ ) and procedures performed in July or August $(\mathrm{OR}=2.08 ; \pm 95 \% \mathrm{CI}: 1.16-3.72, \mathrm{P}=0.01)$ were associated with a higher probability of developing a complication (Table 2).

Variables predictive of a complication with a $\mathrm{P}<0.15$ on univariate analysis were age $(\mathrm{P}=0.14)$, female gender $(\mathrm{P}<0.01)$, persistent AF $(\mathrm{P}<0.12)$, procedures performed in July or August $(\mathrm{P}<0.01)$, and clopidogrel therapy $(\mathrm{P}=0.06)$. Multivariate analysis incorporating these variables demonstrated that female gender $(\mathrm{OR}=2.27 ; \pm 95 \%$ CI: $1.31-2.57, \mathrm{P}<0.01)$ and procedures performed in July or August $(\mathrm{OR}=2.10 ; \pm 95 \% \mathrm{CI}: 1.16-3.80, \mathrm{P}=0.01)$ were independently associated with periprocedural complications. There was no significant interaction between these variables.

\section{Vascular Complications and Pericardial Tamponade}

Vascular access complications constituted the majority of complications in this study (54\%). On multivariate analysis, female gender $(\mathrm{OR}=4.40 ; \pm 95 \% \mathrm{CI}: 1.72-7.75, \mathrm{P}<$ 0.01 ), clopidogrel therapy (OR $=4.70 ; \pm 95 \%$ CI: $1.43-$ $13.53, \mathrm{P}=0.01$ ), and procedures performed in July or August $(\mathrm{OR}=2.71 ; \pm 95 \% \mathrm{CI}: 1.25-5.87 ; \mathrm{P}=0.01)$ were independent risk factors of a vascular complication. Among the 31 patients with a vascular complication, 12 patients had a major hematoma that required transfusion, 17 patients had an arteriovenous fistula, and 2 patients had a pseudoaneurysm of the femoral artery. Surgical repair was performed in 9 of 19 patients who had an arteriovenous fistula or pseudoaneurysm. In the remaining patients, there was spontaneous resolution. There was no difference in the prevalence of vascular and other complications among patients who had RFA without discontinuing warfarin and those who discontinued warfarin and used LMWH as a bridge.

The second most prevalent complication was pericardial tamponade, which accounted for 35\% of all complications. On multivariate analysis, prior RFA for AF was the only independent risk factor for pericardial tamponade $(\mathrm{OR}=3.32$; $\pm 95 \%$ CI: $0.95-11.61, \mathrm{P}<0.05$, Fisher's exact test). Including month of the year, there were no other predictors of pericardial tamponade.

\section{Discussion}

\section{Main Findings}

The main findings of this study demonstrate that: (1) at an academic teaching institution, the complication rate of RFA for $\mathrm{AF}$ is $3.5 \%$ per procedure, including a vascular complication in $1.9 \%$ and pericardial tamponade in $1.2 \%$ of the patients; (2) female gender, procedures performed in July or August, and therapy with clopidogrel are independent predictors of vascular complications, whereas a prior RFA for $\mathrm{AF}$ is the only independent predictor of pericardial tamponade; (3) the prevalence of thromboembolic events after RFA of AF appear to be low, $0.2 \%$; (4) there does not appear to be any association between the ablation strategy, total duration of radiofrequency energy application, total procedure time, or case volume and the probability of developing a complication; and (5) with the ablation technique employed, the risk of PV stenosis is very low, $<0.1 \%$, and there are no cases of phrenic nerve palsy, atrioesophageal fistula, or procedurerelated deaths in $>1,200$ patients after $>1,600$ procedures.

\section{Vascular Complications}

In this study, female gender, clopidogrel therapy, and procedures performed in the months of July or August were independently associated with vascular complications. The explanation for a gender difference in the prevalence of vascular complications may be the variability in vascular anatomy between men and women. The ideal site for femoral venous access should be through the common femoral vein since the vessel is larger and easily compressible. However, women have a significantly shorter common femoral artery than men $(37.9 \pm 12.7 \mathrm{~mm}$ vs $46 \pm 17.2 \mathrm{~mm} ; \mathrm{P}<0.01),{ }^{6}$ which may lead to inadvertent access proximal or distal to the common femoral vein.

The increased risk of procedure-related bleeding with clopidogrel has been well established in the surgical literature and its use is a risk factor for peripheral vascular complications in patients undergoing cardiac catheterization. ${ }^{7,8}$ Consistent with the findings of prior studies, the risk of vascular complications was not any higher among the relatively small group of patients who had a therapeutic INR during the procedure than the rest of the study subjects who discontinued warfarin and used LMWH prior to the procedure. ${ }^{9}$

This study demonstrated that procedure performed in July or August is also an independent risk factor. The academic year starts in the month of July and vascular access is usually the first task new trainees encounter. There are usually 8 trainees over a 2 -year period. It has been long recognized that complications may be higher early in the academic year at teaching institutions, often referred to as the "July Effect." ${ }^{10-12}$ However, in this study, except for vascular complications there was no relationship between other complications and month of the year probably because of close supervision of the trainees by experienced attending physicians. Nevertheless, academic teaching institutions must be aware of this "July Effect" and incorporate measures of close supervision and review of the appropriate techniques to decrease the rate of complications, particularly vascular access. One approach may involve limiting vascular access for RFA procedures until sufficient proficiency is confirmed.

It is possible that placement of fewer venous sheaths through the same femoral vein, particularly in women who 
have shorter veins, may reduce the risk of vascular complications. If mapping and ablation could be performed using the same catheter, then one less venous sheath would be necessary. Therefore, improvements in current ablation techniques and technologies may also be helpful to decrease vascular complications. Whether using a micropuncture venous access technique with or without the guidance of vascular ultrasound will reduce vascular complications remains to be determined.

\section{Pericardial Effusion and Cardiac Tamponade}

Prior RFA for AF was an independent risk factor for pericardial tamponade in this study. In a prior study, significant variations in the transmural thickness of the left atrial myocardium were reported. ${ }^{13}$ It is possible that variability in the anatomy and tissue architecture of the left atrium may predispose to recurrent myocardial perforation and pericardial tamponade.

Another study demonstrated that RFA results in scarring and fibrosis of the atrial wall with subsequent thinning. ${ }^{14}$ With the use of open-irrigation catheters capable of creating large transmural lesions, and with more extensive ablation particularly in patients with persistent AF, prior RFA appears to be an important risk factor for pericardial tamponade. This observation emphasizes the need to minimize the extent of ablation by more precise and specific identification and elimination of drivers of AF; to eliminate the need for repeat ablation procedures as much as possible; and to improve the existing ablation technologies such that extensive fibrosis/scarring and myocardial thinning is minimized or avoided at best. Whether high resolution imaging of the left atrium and the PVs by MRI prior to RFA will be helpful to identify anatomical variations and extent of myocardial scarring and thinning particularly after previous RFA remains to be determined. ${ }^{15}$

\section{Thromboembolic Events}

Thromboembolic events were observed in $<0.5 \%$ of the patients in this study. Experience of the operators with the technique, immediate and aggressive intraprocedural anticoagulation with a target activated clotting time (ACT) $>300$ seconds, bridging with LMWH and continuing anticoagulation for $\geq 3$ months after the RFA may have contributed to the low incidence of thromboembolic events. Furthermore, anticoagulation was never reversed with protamine, which may predispose to a prothrombotic state early after the procedure. Performing RFA with a therapeutic INR may have also prevented thromboembolic events at least among patients in whom warfarin was not discontinued prior to the procedure. $^{9}$

\section{Case Volume, Atrioesophageal Fistula, Phrenic Nerve Palsy, PV Stenosis, and Mortality}

Atrioesophageal fistula has been reported as an infrequent, however, potentially fatal complication of catheter ablation along the posterior left atrium, particularly with ablation catheters capable of creating large and deep lesions. After recognition of this complication, the esophagus has been routinely visualized by barium swallow and applications of radiofrequency energy in the immediate proximity of the esophagus have been minimized. Furthermore, the power has been limited to a maximum of $25 \mathrm{~W}$ along the posterior wall, and omeprazole has been prescribed for 2-4 weeks after RFA to reduce gastric acidity. It is likely that these measures have been helpful in prevention of atrioesophageal fistula in $>1,600$ cases.

There were no cases of phrenic nerve palsy in this series and PV stenosis of $90 \%$ occurred in only one PV, underscoring the importance of avoiding applications of radiofrequency energy within the PVs. However, because the PVs were not routinely assessed after the RFA by CT or MRI, it is possible that asymptomatic PV stenosis was not recognized.

The annual case volume of the 9 operators in this study was not associated with the risk of complications in this study. However, each one of the operators in this study had $>5$ years experience with RFA of AF and had performed at least several hundred cases. There was no procedure-related mortality in this study, reassuring the safety of the procedure.

\section{Prior Studies}

Previous studies have shown that complications of RFA for AF are relatively common and should be carefully considered during patient selection. In a recent worldwide survey that included 182 centers, ${ }^{16}$ the overall complication rate was $4.5 \%$ with a similar frequency of tamponade and peripheral vascular complications, $1.3 \%$ and $1.5 \%$, respectively. In another multicenter registry from 32 centers, the overall complication rate was $3.9 \% .^{2}$

Consistent with the findings of this study, a prior study demonstrated that women were more likely to experience vascular complications than men. ${ }^{7,17}$ An overall complication rate of $5 \%$ with age $>70$ years and female gender as predictors of major complications were reported in another study. ${ }^{18}$ However, the novel findings of this study include the adverse effect of concomitant therapy with clopidogrel on vascular complications, the higher risk of vascular complications early during the academic teaching year, and increased risk of pericardial tamponade after prior RFA for AF.

\section{Limitations}

A limitation is that the findings of this study may not be applicable to other ablation strategies or technologies and only relate to the technique described using an open-irrigation-tip ablation catheter. A second limitation of this study is that, because the event rate was small despite a large sample size, all predictors of complications, particularly for the infrequent ones, may not have been identified. Finally, this study was performed at a single center and may not be generalized to all practices.

\section{Clinical Implications}

Most of the perioperative complications of RFA for AF relate to vascular access, specifically in women and those who receive clopidogrel. Therefore, caution should be exercised and close supervision should be provided during obtaining vascular access particularly early in the academic year. The need to continue clopidogrel into the perioperative phase should be carefully reviewed prior to the procedure. Ablation strategies and technologies that eliminate the need for insertion of multiple venous catheters may also be helpful in reducing the risk of vascular complications.

Because prior RFA for AF is associated with an increased risk of pericardial tamponade, limiting the extent of ablation, 
alternative sources of energy or ablation technologies that do not result in extensive myocardial scarring and thinning, improvements in ablation techniques that reduce the need for repeat procedures, and imaging of the atrial myocardium and atrial geometry prior to ablation may be helpful to reduce the risk of tamponade.

\section{References}

1. Piccini JP, Lopes RD, Kong MH, Hasselblad V, Jackson K, Al-Khatib SM: Pulmonary vein isolation for the maintenance of sinus rhythm in patients with atrial fibrillation: A meta-analysis of randomized, controlled trials. Circ Arrhythm Electrophysiol 2009;2:626-633.

2. Bertaglia E, Zoppo F, Tondo C, Colella A, Mantovan R, Senatore G, Bottoni N, Carreras G, Coro L, Turco P, Mantica M, Stabile G: Early complications of pulmonary vein catheter ablation for atrial fibrillation: A multicenter prospective registry on procedural safety. Heart Rhythm 2007;4:1265-1271.

3. Cappato R, Calkins H, Chen SA, Davies W, Iesaka Y, Kalman J, Kim YH, Klein G, Packer D, Skanes A: Worldwide survey on the methods, efficacy, and safety of catheter ablation for human atrial fibrillation. Circulation 2005;111:1100-1105.

4. Wieczorek M, Hoeltgen R, Akin E, Salili AR, Oral H, Morady F: Results of short-term and long-term pulmonary vein isolation for paroxysmal atrial fibrillation using duty-cycled bipolar and unipolar radiofrequency energy. J Cardiovasc Electrophysiol 2010;21:399-405.

5. Good E, Oral H, Lemola K, Han J, Tamirisa K, Igic P, Elmouchi D, Tschopp D, Reich S, Chugh A, Bogun F, Pelosi F Jr, Morady F: Movement of the esophagus during left atrial catheter ablation for atrial fibrillation. J Am Coll Cardiol 2005;46:2107-2110.

6. Schnyder G, Sawhney N, Whisenant B, Tsimikas S, Turi ZG: Common femoral artery anatomy is influenced by demographics and comorbidity: Implications for cardiac and peripheral invasive studies. Catheter Cardiovasc Interv 2001;53:289-295.

7. Castillo-Sang M, Tsang AW, Almaroof B, Cireddu J, Sferra J, Zelenock GB, Engoren M, Kasper G: Femoral artery complications after cardiac catheterization: A study of patient profile. Ann Vasc Surg 24:328-335.

8. Herman CR, Buth KJ, Kent BA, Hirsch GM: Clopidogrel increases blood transfusion and hemorrhagic complications in patients undergoing cardiac surgery. Ann Thorac Surg 89:397-402.

9. Di Biase L, Burkhardt JD, Mohanty P, Sanchez J, Horton R, Gallinghouse GJ, Lakkireddy D, Verma A, Khaykin Y, Hongo R, Hao S, Beheiry S, Pelargonio G, Dello Russo A, Casella M, Santarelli P, Santangeli P, Wang P, Al-Ahmad A, Patel D, Themistoclakis
S, Bonso A, Rossillo A, Corrado A, Raviele A, Cummings JE, Schweikert RA, Lewis WR, Natale A: Periprocedural stroke and management of major bleeding complications in patients undergoing catheter ablation of atrial fibrillation: The impact of periprocedural therapeutic international normalized ratio. Circulation 121:25502556.

10. Haller G, Myles PS, Taffe P, Perneger TV, Wu CL: Rate of undesirable events at beginning of academic year: Retrospective cohort study. BMJ 2009;339:b3974.

11. Lesar TS, Briceland LL, Delcoure K, Parmalee JC, Masta-Gornic V, Pohl H: Medication prescribing errors in a teaching hospital. JAMA 1990;263:2329-2334.

12. Phillips DP, Barker GE: A July spike in fatal medication errors: A possible effect of new medical residents. J Gen Int Med 2010;25:774779 .

13. Hall B, Jeevanantham V, Simon R, Filippone J, Vorobiof G, Daubert $\mathrm{J}$ : Variation in left atrial transmural wall thickness at sites commonly targeted for ablation of atrial fibrillation. J Interv Card Electrophysiol 2006; 17:127-132.

14. Peters DC, Wylie JV, Hauser TH, Kissinger KV, Botnar RM, Essebag V, Josephson ME, Manning WJ: Detection of pulmonary vein and left atrial scar after catheter ablation with three-dimensional navigatorgated delayed enhancement MR imaging: Initial experience. Radiology 2007;243:690-695.

15. Oakes RS, Badger TJ, Kholmovski EG, Akoum N, Burgon NS, Fish EN, Blauer JJ, Rao SN, DiBella EV, Segerson NM, Daccarett M, Windfelder J, McGann CJ, Parker D, MacLeod RS, Marrouche NF: Detection and quantification of left atrial structural remodeling with delayedenhancement magnetic resonance imaging in patients with atrial fibrillation. Circulation 2009;119:1758-1767.

16. Cappato R, Calkins H, Chen SA, Davies W, Iesaka Y, Kalman J, Kim YH, Klein G, Natale A, Packer D, Skanes A, Ambrogi F, Biganzoli E: Updated worldwide survey on the methods, efficacy, and safety of catheter ablation for human atrial fibrillation. Circ Arrhythm Electrophysiol3:32-38.

17. Patel D, Mohanty P, Di Biase L, Sanchez JE, Shaheen MH, Burkhardt JD, Bassouni M, Cummings J, Wang Y, Lewis WR, Diaz A, Horton RP, Beheiry S, Hongo R, Gallinghouse GJ, Zagrodzky JD, Bailey SM, Al-Ahmad A, Wang P, Schweikert RA, Natale A: Outcomes and complications of catheter ablation for atrial fibrillation in females. Heart Rhythm7:167-172.

18. Spragg DD, Dalal D, Cheema A, Scherr D, Chilukuri K, Cheng A, Henrikson CA, Marine JE, Berger RD, Dong J, Calkins H: Complications of catheter ablation for atrial fibrillation: Incidence and predictors. J Cardiovasc Electrophysiol 2008;19:627-631. 